by Jarotsky and Waldeyer in which this occurred. be necessary, either by the finger or by means of The vesicular mole belongs to a class of patholog- tents, or Barnes' bags. A very useful contrivance ical products known as myxomata. (Virchow, Cor- used in the removal of the fleshy mole is the Beecher nil, Ranvier, Malassez and de Sinéty, have demon-|forceps, termed by him a "New Abortion and Plastrated the identity of the vesicular mole with myxo- centa Forceps." A description can be found in the mata of other regions.

An analogous degeneration of the placenta has been described by Virchow and Hildebrandt as "fibrous myxoma" of the placenta. Schrœder quotes cases of "diffuse myxoma" of the placenta by Breslau, Eberth, Spaeth and Wedl.

A case of myxoma, or hyperplasia of the choronic villi, is related by Dr. Sinclair, in Vol. I, of the Publications of the Massachusetts Medical Society.

Different synonyms are: Hydatid, or vesicular mole; cystic degeneration of the chorion and placenta; dropsy of chorional villi; myxoma of the placenta.

TIME OF THE FIRST HÆMORRHAGE AND ITS DURATION IN HYDATID GESTATION.

\begin{tabular}{|c|c|c|c|c|c|c|}
\hline $\begin{array}{l}\text { Names } \\
\text { of Authors. } \\
\text { Dumau seau, }\end{array}$ & Time of ist & $\begin{array}{l}\text { of ist } \\
\text { rrhage. } \\
\text { days }\end{array}$ & $\begin{array}{l}\mathrm{Ti} \\
\mathrm{Del} \\
8 \mathrm{~m}\end{array}$ & $\begin{array}{l}\text { ne of } \\
\text { ivery. } \\
\text { onths }\end{array}$ & & $\begin{array}{l}\text { uration } \\
\text { Flow. } \\
\text { months. }\end{array}$ \\
\hline Mme. Boivin, & 45 & & 4 & “ & $31 / 2$ & \\
\hline Littre, & & mos. & 6 & ، & $4 / 2$ & “ \\
\hline Crowfort, & 3 & & 7 & " & 4 & "6 \\
\hline Louville, & 3 & " & 7 & “" & 4 & “" \\
\hline Percy, & & “" & 8 & “ & 5 & “ \\
\hline Mme. Boivin, & 3 & & 8 & “6 & $4^{1 / 2}$ & “ \\
\hline Pichart, & 4 & "“ & 4 & “" & & \\
\hline Millot, & 4 & " & 4 & “ & & \\
\hline Delamotte, & 5 & “ & $51 / 2$ & “ & I 5 & days. \\
\hline Percy, & 6 & “ & 9 & " & 3 & months. \\
\hline Bremser, & 7 & " & 8 & “" & I & " \\
\hline Jolly, & 8 & “" & 10 & “ & 2 & i6 \\
\hline Bandelocque, & II & “ & II & “6 & & \\
\hline " & 16 & “" & I 4 & ، & & \\
\hline$\underset{\text { Rosenthal, }}{\text { (6) }}$ & 6 & “" & 7 & "، & $\mathbf{I}$ & " \\
\hline " & I I & “ & 16 & " " & 5 & “ \\
\hline
\end{tabular}

DURATION OF HYDATID GESTATION. OBSERVATION IN CASES.

\begin{tabular}{|c|c|}
\hline Women & $\underset{66}{\text { delivered }}$ \\
\hline ، & 6) \\
\hline \&6 & \&6 \\
\hline 66 & " \\
\hline 16 & 6) \\
\hline 16 & 6 \\
\hline 66 & 66 \\
\hline 6. & " \\
\hline 6 & if \\
\hline 86 & 86 \\
\hline
\end{tabular}

at I4 months, I I 10 16

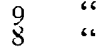

8 " " 8 dys.

7 64 $5 \%$ " $\begin{array}{ll}4 & 6 \\ 3 & 6\end{array}$

Total,.

TrEatMENT.-The treatment of all forms of molar pregnancies consists in the complete removal, whenever practical, of all the diseased tissue. The special treatment is of the hæmorrhage. General measures and expectant treatment if slight; tamponning if it be severe. The expulsion of a few vesicles during the pregnancy does not affect the treatment. It is a common thing to recommend oxytocics, preferably ergot, but if this fails to insure the expulsion of the mass, recoure must be had to other methods. We can scoop out all we can reach with our hands, this implies a dilated or dilatable os, and it will be fortunate if we meet with this. If not, dilatation will
Medical News, I883, xlii, 259. The advantages are: It is adapted to the removal of the foetus in abortion, and the placenta, moles, etc., taking hold of a larger portion at a time without in the least imperilling the mother's parts. Besides what may be caught in the jaws, if any portion of the mass extend beyond and between the blades behind the shoulders, they are also held without being crushed through, as would be the case in the Bond instrument, with its closely approximate blades; and greater purchase is given upon the mass. The fenestrum allows a protrusion through it, and prevents the crushing through the placenta without the ability to remove a portion of the mass other than in shreds. It can also be used as a dilator.

In some cases the moles adhere to the uterine wall as firmly as a placenta glued by fibrinous deposits. In such cases a curette is necessary. If the diseased tissues be not removed entirely the portions remaining may give rise to grave and exhausting discharges or the recurrence as before mentioned.

It is also important to remember in this connection that $t$ win pregnancies may occur in which vesicular degeneration affects the membranes of but one ovum. It is well, therefore, to bear in mind the possibility of this, and that the sound ovum may develop to full development.

Even after evacuating the uterus there may be a good deal of hæmorrhage. If so, repeat ergot, use abdominal pressure, and give iced drinks, etc. The slow convalescence may be hastened with iron, nux, quinine, nutritious food, wines, etc., as the case may indicate.

517 Pine St., Philadelphia.

\section{PEROXIDE OF HYDROGEN AS A REMEDIAL AGENT.}

Read before the St. Louis Medical Society, February 4, 1888. BY I. N. LOVE, M.D.,

CONSULTING PHYSICIAN TO THE CITY hOSPITAL, ST. LOUIS,

I am aware that there is a disposition upon the part of some workers in the profession to decry the merits of those whose efforts tend in the direction of therapeutic investigation, and the application of remedies to the relief of disease, the rather appreciating pathological research and the study of the phenomena of disease.

Fully recognizing the importance of closely and carefully scrutinizing the anatomical, physiological and pathological panorama that may be presented to our view, I cannot refrain from suggesting that after all the main object to be attained is the relief of suffering and the prolongation and saving of human life. The most profound pathologist would be powerless for good did he not have as an ally the delver among drugs searching for the means of mastering the microbes which he has discovered, and the studious, thoughtful practical physician, accomplishes 
the greatest amount of good and secures the most substantial success who promptly applies the knowledge gained by both workers, and all are co-laborers aiding the securement of that grand millenium when man will pass from the cradle to his second infancy without the shadow of suffering or a thought of disease.

Huxley has said that an exhaustive study of drugs on the part of physicians, was not necessary to their proper application to the cure of disease any more than a complete knowledge of the manufacture of surgical instruments was necessary to their successful use by the surgeon; however, a practical familiarity with the make-up and mode of action of these medical and surgical tools is essential to their graceful and efficient use.

The medicament to which I propose to direct your attention in this paper is the "Peroxide of Hydrogen," the formula of which is $\mathrm{H}_{2} \mathrm{O}_{2}$, and which was discovered in 1818 by Thenard, by adding dilute acids to peroxide of barium. Meissner, in $186_{3}$, proved its presence in the rainwater collected during thunder storms, and this has been corroborated by Schönbein, Struve and others. The usual preparation of a solution of peroxide of hydrogen depends upon the decomposition of barium peroxide by hydrocloric acid (carbonic or hydrofluoric acid may be used) in the presence of ice cold water, and the precipitation of the newly formed barium chloride by means of sulphate of silver. Such solutions usually contain about 3 to 5 per cent. of the peroxide, and are concentrated by freezing, the last portions of water being evaporated in vacuo over sulphuric acid at a temperature not exceeding $68^{\circ} \mathrm{F}$. In this form it is a colorless, transparent, syrupy liquid, with a specific gravity of $1.45^{2}$, does not congeal at $\mathbf{2} 2^{\circ}$ below zero (F), volatilizing slowly and without decomposition at the ordinary temperature. It is decomposed when exposed to the sunlight, or when heated or brought into contact with charcoal, silver, gold, the platinum metals, the oxides of maganese, alkalies and other compounds. In this concentrated form the peroxide, if brought under the conditions favorable, may decompose with explosive violence, and in the presence of the oxides of the metals mentioned they are reduced to the metallic state.

Many other bodies act less energetically or are oxidized. Litmus and tumeric paper are gradually bleached, and the skin may be turned white by its application, accompanied by itching. In the strength to which I am now referring it is without odor and has a harsh and bitter taste, soluble in water in all proportions, which solutions are decomposed by the same agents as the pure compounds, but less vio. lently. They are made more permanent by adding a small amount of mineral acid.

The commercial peroxide of hydrogen is a 3 per cent. aqueous solution, and is prepared on a large scale for the bleaching of animal products such as feathers, hair, silk, bone, etc. It is known as "ten volume peroxide of hydrogen," owing to the fact that it yields about ten volumes of active oxygen which may be estimated by adding a sufficient amount of sulphuric acid, and afterwards a standardized solution of potassium permanganate as long as the latter is decolorized. From its very nature this agent should be a powerful antiseptic and a destroyer of microbes; anything which accomplishes oxidation as rapidly, if it can be applied safely, must be an excellent application to purulent surfaces for its cleansing effect. It has been administered internally for diabetes, but without success. Its recommendation for some forms of atonic dyspepsia, would seem to be reasonable, since we know that condition to be frequently due to a catarrh of the gastric mucus surface accompanied by excessive secretion and fermentation.

I find there is considerable variation in the effectiveness of solutions coming from different drug stores; this may be due to a failure to protect it from the sunlight. It should be kept in opaque bottles at a temperature not above $77^{\circ}$. I have secured uniform satisfaction from the solution manufactured by the G. Malinckrodt Chemical Co. of St. Louis.

The clinical application of a remedy is the best test of its value. As a contribution to the fund of knowledge upon this subject, I herewith present the following cases:

Scarlet Fever and Diphtheria.-R. H., aged 4 years, an unusually intelligent and interesting boy, developed scarlet fever Dec. 22, 1887. A pronounced case, temperature vibrating for several days from $102^{\circ}$ to $104^{\circ}$, throat quite sore, some disposition to ulceration upon both tonsils. Within a week symptoms much modified, temperature ranging in the neighborhood of $100^{\circ}$, where it remained for four days, child being quite playful but not permitted to get out of bed. At this time diphthesia became a complication, involving the pharynx and the nasal passages. The secretions from all the mucus surfaces were very profuse and purulent in character, and suffocation at times seemed imminent from its accumulation, and the odor was extremely offensive to the patient as well as the attendants. A well organized fibrinous exudation appeared over the surface of the tonsils well forward to the palate, and upward to the posterior nares. The submaxilary and sublingual glands were much enlarged and engorged. Wherever a mucus surface was visible, if not covered with diphtheria membrane, it was violently inflamed nearly to the point of ulceration, and exuding a purulent and almost disgusting discharge. Temperature ranged in the neighborhood of $104^{\circ}$ and $105^{\circ}$, and almost constant paroxysmal cough was present, due to the general irritation, and accumulated secretions, and at times a marked asthma was present, owing to reflex irritation, dependent upon the inflammation of the posterior nares. The general conditions were alarming, the child being almost in a state of frenzy, owing to his many discomforts. I shall not give in detail the notes of the case, as I only cite it as an illustration of the value of a particular remedy to relieve a particular series of symptoms.

Having been using the peroxide of hydrogen in various strengths for some months as a purifying and stimulating wash for purulent ulcers, sinuses, and 
fistula, as well as diphtheria, I concluded to use it as an application in this case. Diluting it with one part to two of water for application to the nasal passages by means of a syringe, and using it in its purity by means of probang and absorbent cotton to the pharnyx. I soon had the satisfaction of seeing the pus, and accumulated mucus cleaned out from all the surfaces as if by magic. The child was a bright little hero, and, though semi delirious, he helped materially in its application, and also in the the removal of the oxidized purulent matter. The nasal passages, front and back, were soon cleared our, the fauces as well were kept in a comparatively clean condition. A good opportunity was now presented for applying the solution in its purity to the nembrane direct, and the disintegration of the same was accomplished after repeated application in a very decided manner. Wherever the solution came in contact with organic matter, a marked effervescence and bubbling ensued, and a breaking down of the accumulation or exudation and throwing off of the same occurred. The beneficial effect of the applicacation was apparent, all the distressing symptoms were much abated, and within three or four days they had passed away. One thing quite noticeable was, the fact that the constant spasmodic cough subsided after the removal of the purulent secretions from the nasal passages.

The success in this case was similar to that in six other cases, and I quote this one as illustrating the class, not desiring to indulge in repetition by reporting them all. This child was in a most dangerous condition for many days and nights, and I do not claim that the peroxide of hydrogen saved him; but it certainly helped to do it, in that it enabled me to combat the local poison, acting as an antiseptic, a germicide of the most pronounced character, a remover of purulent septic matter and offensive odors, aiding in the conservation of comfort to patient and attendants.

Constitutional measures were, of course, never lost sight of, constant attention being directed to excretion, sedation, stimulation and nutrition. Other local measures were of course used, the peroxide serving as a means of "clearing the track" for the application of soothing and healing ointments to the nasal passages and the spraying of all the surfaces with Listerine and other remedies as indicated.

En passant at this point permit me to remark that I have no patience with the practitioner who permits himself to be overcome by a physical, mental and scientific inertia, so that he can sit idly by and trust entirely to the vis medicatrix natura. If one's house is on fire and he trusts to nature instead of turning on the hose, the chances are that he will sleep on the commons unless a friend takes him in. The "therapeutic nihilist" should change his calling. The practitioner with no faith in physic, who, like Solomon, cries out "All is vanity," gives evidence that he has mistaken his vocation, or, like Solomon, indicates that it is time for him to abdicate. What would one think of a soldier who was ever decrying the merits of his cause and gun? Either that he has a poor cause and an inefficient gun, or does not understand the one nor know how to use the other. In the management of no disease, in my judgment, is it so necessary for the attendant to be ever on the alert as in diphtheria. He should sleep on his arms, so to speak, with one eye open; anticipate his enemy rather than run the risk of a surprise. Well supplied with ammunition, ready to use it "not too much but just enough," and possess an abiding faith in its efficacy. In wrestling with disease let us pursue the course with remedial agents that we do with friends; study them, try them, weigh them in the balance thoroughly, and if not found wanting adopt them and trust them. Then let us stick to them as long as they prove faithful. If they fail us and a better one be presented, accept it if it stand the test and prove worthy. In short, let us not drop an old friend for a new unless the first prove false and the second give evidence of virtue. As an adjuvant in arresting the destructive tendency of diphtheria I am persuaded that the peroxide of hydrogen will stand the test of tim.e. Purulent Ozena and Chronic Nasal Catarrh.-I have applied the peroxide of hydrogen in strengths varying from I part to 3 or 6 of water in four cases of the above character during the past month. Very favorable reports have been given me, enough so to justify me in considering it of great value in this trouble. A sufficient time has not elapsed to enable me to determine whether it will secure a permanent cure. The application was made three times daily. Acute Coryza. - The peroxide in the proportion of I to 4 of water was applied freely by means of a syringe through the nostrils, a hard rubber syringe gently throwing about 2 tablespoonfuls into each nostril while the head is thrown back ward. It passes back through the posterior nares, carrying the completely oxidized mucus secretion with it. It is then applied to the fauces in the same manner. A free sneezing and perfect discharge follows. The application is made about once in four hours in the beginning and less frequently later. Three such cases were greatly relieved after first application and cured inside of a day or two. It is well known that influenza, in some cases at least, is dependent upon some irritating germ, and possibly the agent used above killed the microbe.

Whooping-cough.-In two cases where the paroxysms were frequent and violent I have had great satisfaction in seeing the frequency and severity much modified by the use of the peroxide of hydrogen ( $I$ to 4) twice daily, and the attack was unquestionably cut short.

Reflex Asthma.-Two cases of reflex asthma intercurrent during an attack of diphtheria and a general catarrhal fever, dependent upon the irritation in the post-nasal space, were promptly relieved after a few applications of the peroxide ( $\mathrm{I}$ to 4 ).

Follicular Tonsillitis. - Very satisfactory results were obtained by using the remedy as a gargle ( $\mathrm{I}$ to 3) every two or three hours. Listerine, callendulæ, tincture of iron and other soothing, stimulating and astringent remedies were used by the atomizer between the intervals.

Hay Fever.-I have not used the remedy in this trouble, but would suggest from the manner of its action that it is worthy of trial. 
Cancer of the Womb.-In this affection I have had great satisfaction in using the peroxide in its purity as a cleanser, deodorizer, and stimulator of healing in that portion of the ulceration probably dependent upon the irritating effect of accumulated purulent matter. The gratification and comfort to patient and attendants secured by the application well repaid its use. One who has never observed the horrible stench in the room of a neglected cancer of the womb can have no conception of the value of the drug in this connection. Dr. Joseph Grindon, a dermatologist of St. Louis, informs me that he has used the agent to remove pigment spots from the skin. This is the main remedy furnished by dealers to weakminded women for blonding the hair.

It is needless for me to continue to cite cases and conditions where the peroxide of hydrogen will prove of value. I think it worthy of trial in gonorrhoea.

After a six months' trial of the peroxide of hydrogen, considering the nature of the agent and its effect upon purulent matter and bacteria, I feel justified in concluding:

I. The peroxide of hydrogen is a most efficient means of cleansing purulent surfaces, deep cavities and sinuses, and stimulating the healing process in ulcerating parts.

As a destroyer of microbes it is of great value as a local application in diphtheria and scarlet fever, ozæna, coryza and whooping-cough.

3. For the above reasons it should prove of value in gonorrhoea, hay fever, and similar disturbances probably dependent upon specific germs.

\section{FACTS IN RELATION TO EMACIATION.}

$$
\begin{gathered}
\text { Abstract of Paper read before the Medical Society of the } \\
\text { District of Columbia. } \\
\text { BY THOMAS TAYLOR, M.D., } \\
\text { OF WASHINGTON. }
\end{gathered}
$$

For several years past I have devoted much of my time to the crystallography of animal fats, and have examined, crystallized and photographed the fats of several huridred animals, and a few vegetable oils. In the prosecution of this inquiry I observed incidentally, that the fats of several monkeys, victims of consumption, when rendered, strained and cooled, at a temperature of about $70^{\circ} \mathrm{F}$. according to my usual method of treating fats in order to crystallize them, exhibited but a trace of the solid fats; the mass consisted principally of olein. From this fact my attention was directed to the consideration of the fat of human beings, subjects of emaciating diseases, from whatever cause. I have tested the fats of three consumptives who were greatly emaciated. The fats were crystallized in the usual manner-boiled, strained and cooled, at $70^{\circ} \mathrm{F}$ - - and, when examined, were found to be nearly destitute of solid fats, olein largely predominating.

While the cases cited are insufficient data for determining what may be the invariable condition of the fats of emaciation, I deem the facts thus far observed, worthy of attention, and I propose to continue these researches in order to ascertain whether the conditions I have stated are constant. If in the animal economy, it can be shown that there is a greater tendency to oxidize the solid fats than the oil, in cases of high temperatures and emaciation, valuable information will be gained.

With regard to the composition of fats in general, they consist of three distinct fats, viz: olein, palmatin and stearin. These are known as glycerides of the fatty acids oleic, palmatic, and stearic. Early chemists applied the term margarin to a substance they believed to be a simple fat, but modern chemistry has demonstrated that this substance is merely a combination of palmatin and stearin. It has been demonstrated that the fat of milk and butter contains but a trace of stearin, and that it is composed mostly of palmatin and olein, and it is also stated on high authority, that the fat of man is of similar composition.

In my investigations relating to the forms of animal fat, I have observed that the crystals of human fat have a marked resemblance to crystals of milkbutter, suggesting the importance of the use of milkbutter as the proper form of fat for man, and superior to fats which consist largely of stearin, such as some oleomargarines I have tested.

According to modern chemistry s' earin requires a temperature of $x 44^{\circ} \mathrm{F}$. to melt it, and in each succeeding fusion a still higher temperature is required. For this reason the common fats cannot be as well adapted for the sick as butter, which melts at blood-heat. Therefore I think it might be well to test the value of pure butter as a substitute for other forms of fat now in use in cases of emaciation. In this case I would suggest that butter used for this purpose be boiled and strained to remove its casein, the casein of milk frequently proving very indigestible and unbearable to a weak stomach.

Milk, the natural food of man, contains all the essential proximate principles necessary to build up a perfectly healthy human being; but the bitter fat of milk contains but a small proportion of nitrogenous matter as compared with the milk from which it is made; therefore, butter of itself does not afford sufficient nitrogenous matter to sustain life but for a limited period. As it is desirable to make sure that the diet contains a proper amount of nitrogenous matter, in an acceptable form, I recommend the use of peptonized beef, in other words, digested beef, in connection with butter so treated. Such a combination would build up the vital tissues.

As the solid fats of butter contain a larger amount of carbon than is found in the same amount of oil, the oxidation of these solid fats would contribute more animal heat than would the oxidation of the oil. In this process water would be formed, the elimination of which would lower the temperature of the body, thus rending to arrest the destruction of the tissues.

The "Revue Médico-Pharmaceutique is the title of a new journal recently begun in Constantinople, and edited by M. Apéry. 